\title{
Self-care training and informational support of patients with a mechanical heart valve on the international normalized ratio and bleeding complications
}

\author{
Shirdel Zandi ${ }^{1}$, Behzad Imani², Safarpour Gholamreza ${ }^{3}$ \\ ${ }^{1}$ MS Student, Department of Operating Room, Student Research Committee, Hamadan University of Medical Sciences, \\ Hamadan, Iran \\ 2Department of Operating Room, School of Paramedicine, Hamadan University of Medical Sciences, Hamadan, Iran \\ ${ }^{3}$ Department of Heart Surgery, School of Medicine, Hamadan University of Medical Sciences, Hamadan, Iran
}

Kardiochirurgia i Torakochirurgia Polska 2021; 18 (2): 80-86

\begin{abstract}
Aim: The aim of the study was to determine the effect of self-care training and informational support of patients with a mechanical heart valve on the international normalized ratio (INR) and bleeding complications.

Material and methods: Design: A quasi-experimental study. Participants were recruited via convenience sampling and were randomly divided into two groups: control $(n=80)$ and intervention $(n=80)$. Participants in the control group received only routine training; in addition, the intervention group received 6 sessions of self-care training and 6 months of informational support. Monthly the level of INR and incidence of bleeding were determined. Data were analyzed using the independent $t$-test and $\chi^{2}$ in SPSS16 software at a significance level of 0.05 .

Results: During 6 months of follow-up, except for the third month, the frequency of INR levels in the therapeutic target range $(2.5-3.5)$ in the intervention group was significantly higher than that in the control group $(p<0.05)$. Also in the intervention group, the incidence of bleeding complications was lower than that in the control group, but this difference was not statistically significant $(p>0.05)$.

Conclusions: Proper self-care training and informational support in patients with mechanical heart valve replacement have positive results. By maintaining self-care, the level of a therapeutic target range of INR can be maintained and the incidence of bleeding complications can be reduced.
\end{abstract}

Key words: self-care, heart valve replacement, international normalized ratio, bleeding complications.

\section{Introduction}

While heart valve replacement as a surgical technique improves survival in the presence of heart valve regurgitation disorders and valve stenosis, it can lead to complications such as prosthetic valve thrombosis or systemic embolism [1, 2]. Due to the high prevalence and risks of these complications, anticoagulant regimens are considered for these patients after surgery, and patients must adhere to this lifesaving drug regimen $[3,4]$. The purpose of oral anticoagulation (OAC) therapy is to induce controlled depression of blood coagulability in order to reduce the risk of thromboembolic complications.

Vitamin $\mathrm{K}$ antagonists (VKAs) such as warfarin and acenocoumarol are currently considered standard drugs for OAC in these patients [5]. The differences observed in anticoagulation control dependent on the type of VKA may result from a shorter half-life of acenocoumarol compared to warfarin and the latter seems to be preferable for patients who are candidates for very prolonged oral anticoagulation therapies (OAT), such as patients with heart valve replacement [6]. In Iran, warfarin is mainly used for anticoagulant therapy in patients with a heart valve prosthesis. However, a previous study showed that the SAMe-TT2R2 (sex female, age, medical history, treatment, tobacco use, race) score appears less effective in predicting unstable anticoagulation with acenocoumarol compared with warfarin [7].

The required VKA dosage is titrated based on the international normalized ratio (INR) [8]. If the drug is taken correctly and the INR level is maintained in the therapeutic target range, anticoagulation treatments can prevent serious complications such as bleeding and embolism, thereby increasing postoperative survival rates and the quality of life among patients $[9,10]$. However, due to the limited range of treatment, this drug can be considered a compli-

Address for correspondence: Behzad Imani PhD, Assistant Professor, Department of Operating Room, School of Paramedicine, Hamadan University of Medical Sciences, Hamadan, Iran, e-mail: behzadiman@yahoo.com

Received: 27.12.2020, accepted: 11.03.2021. 
cation factor for patients [11]. Thus, if the INR is higher than the target treatment range, the patient is prone to bleeding, and in cases below this range, the incidence of thromboembolic events is strengthened [12].

It has been found that several factors such as socioeconomic factors, diet, concomitant medication, underlying disease, knowledge, activity, etc. affect the effects of warfarin and the occurrence of side effects in consumers [13-15]. Accordingly, heart valve replacement patients need to be sufficiently aware of the factors that can affect the individual and take care of themselves against the influential factors. In fact, self-care is a very important behavior in patients with heart failure that can improve treatment outcomes and, in turn, reduce the need for readmission and treatment costs [16-18].

\section{Aim}

Accordingly, the present study aimed to determine the effect of self-care training and informational support of patients with a mechanical heart valve on the INR and bleeding complications.

\section{Material and methods \\ Study design}

The study was designed as a quasi-experimental study to determine the effect of self-care training and informational support of patients with a mechanical heart valve on the INR and bleeding complications.

\section{Participants}

Participants were recruited via convenience sampling. Sampling was performed from August 2019 to September 2020. Among the patients who had been referred for heart valve replacement during this period, 160 people were selected based on inclusion and exclusion criteria and were divided into control and intervention groups with a ratio of $1: 1$.

Inclusion criteria for patients were as follows: 1) having mechanical heart valve prostheses in any position; 2) at least 18 years of age; 3) ability to effectively communicate; 4) receiving only oral warfarin for anticoagulation therapy; and 5) without drug and alcohol abuse; and 6) telephone communication available. The exclusion criteria were as follows: 1) patient with biological prostheses; 2) simultaneous CABG surgery; 3) medical history of coagulation disorders; and 4) known ulcerous disease with bleeding tendency.

\section{Ethical considerations}

Before any intervention, patients were informed of the purpose of the study, and patients were required to sign an informed consent form to begin work. Patients were informed that they were free to leave the study at any time and for any reason without the need for any explanation. Patients were also promised that personal information would remain confidential and that the results of the study would be published collectively or without personal infor- mation. This study is the result of a student thesis that has been registered in Hamadan University of Medical Sciences of Iran with the ethical code IR.UMSHA.REC.1398.403.

\section{Usual care (control) group}

Patients in the control group before and after surgery received only routine hospital training. Pre-surgery training included shaving and washing the surgical site with antiseptic detergents and encouraging spirometry. Postsurgery training also included movement training, nutrition counseling, medication counseling, prothrombin time (PT) and INR tests, and timely visits to the treating physician at specified times. Also, an educational pamphlet was routinely given to the patient for study at home, and the telephone number of the patient education unit was provided to the patient and his/her companion so that they could contact the medical center if necessary.

\section{Intervention group}

The intervention group, in addition to receiving all the training and routine hospital programs, participated in two one-hour training sessions before surgery and in four one-hour training sessions after surgery. In these sessions, content was provided on self-care training for patients receiving mechanical heart valves. Before surgery, the first session was held on the day of admission to the hospital and the second session was held on the day before the patient was admitted to the operating room. After surgery, the first session was held 3 days after surgery, the second session the day before discharge, and the third and fourth sessions the first and second weeks after discharge, respectively. These patients received informational support from the research team during a 6-month followup program.

\section{Educational content}

In this study, educational content were prepared based on performing a self-care educational needs assessment of heart valve replacement patients. For this purpose, at the beginning of the study, a qualitative interview was conducted with several heart valve replacement patients (patients who were in the surgical queue and also patients who had previously undergone this surgery) and they were asked questions about their educational needs. Finally, by performing qualitative content analysis of the interviews, the educational needs of these patients were determined. In order to meet the educational needs of these patients, an educational package was prepared based on the opinion of nursing specialists, cardiac surgeons, nutritionists and rehabilitation specialists. To determine the content validity, the training package was provided to 8 relevant experts and they were asked to express their opinions of the educational content and to comment on whether the content needed to be modified and edited. Finally, based on the opinion of experts, the amount of the content validity ratio (CVR) was calculated to be 0.75 (Table I). 
Self-care training and informational support of patients with a mechanical heart valve on the international normalized ratio and bleeding complications

Table I. Educational content

\begin{tabular}{|c|c|}
\hline Meeting time & Content of the training session \\
\hline \multicolumn{2}{|l|}{ Before surgery: } \\
\hline First session & $\begin{array}{l}\text { Describing the disease, describing surgery as a treatment method, familiarity with the types of valves and the } \\
\text { advantages and disadvantages of each, a guide to conscious and rational choice of surgery, answering questions }\end{array}$ \\
\hline Second session & $\begin{array}{l}\text { Training in self-relaxation methods, familiarity with the operating room environment and cooperation with the } \\
\text { surgical staff, familiarity with the ICU environment and cooperation with nurses, proper breathing, the importance } \\
\text { of coping with nursing procedures, answering questions }\end{array}$ \\
\hline \multicolumn{2}{|l|}{ After surgery: } \\
\hline First session & $\begin{array}{l}\text { Importance of starting activities, surgical wound care and dressing, familiarity with the importance of warfarin } \\
\text { and prescription drugs, answering questions }\end{array}$ \\
\hline Second session & $\begin{array}{l}\text { Infection prevention methods, symptoms of surgical wound infection, prevention and diagnosis of surgical } \\
\text { complications, answering questions }\end{array}$ \\
\hline Third session & $\begin{array}{l}\text { INR and maintenance of treatment levels, compatible diet, warfarin and prevention of drug interactions, } \\
\text { the importance of maintaining a dynamic life, answering questions }\end{array}$ \\
\hline Fourth session & $\begin{array}{l}\text { Efforts to maintain INR at the treatment level, activity compatible, return to normal life, prevention of limitation, } \\
\text { self-relaxation, sexual activity, ways to communicate with the treatment center, risk identification and prevention, } \\
\text { answering questions }\end{array}$ \\
\hline
\end{tabular}

\section{Informational support program}

To provide informational support to the patients in the intervention group, once every 2 weeks, one of the members of the research team, as the person in charge of education, contacted the patients and provided the necessary informational support in the field of self-care. He was also present at the hospital during the follow-up period and communicated with each of the patients in the intervention group who referred to the treating physician to present their INR test results, and discussed their self-care measures. If the person was faced with a new case that required training and counseling, sufficient information would be provided.

\section{Instruments}

In this study, the data collection instrument included three main sections: the demographic and clinical information questionnaire, INR test results, and bleeding accident checklist.

\section{Demographic and clinical information questionnaire}

This questionnaire was used at the beginning of the study and patient baseline information was collected using it. Demographic information included age, height, weight, gender, marital status, employment, education, and residence. Clinical information included body mass index (BMI), hypertension, diabetes, dyslipidemia, smoking habit, alcohol consumption, valve position (aortic, mitral, tricuspid, bivalve), and hospital stay.

\section{INR}

A standard blood test was used to determine the INR of patients and the test sheet was considered as a data collection tool. In this study, based on available resources [19] and the opinion of experts, the INR in the range 2.5 to 3.5 was considered as the therapeutic target range, and mea- sures outside of this range were considered as abnormal rates that needed to be corrected.

\section{Bleeding complications}

In this study, based on the opinion of experts and previous studies [20] a checklist was designed to investigate the incidence of bleeding events, based on which bleeding events were divided into two categories: major hemorrhage complications included macroscopic hematuria, vaginal bleeding, hemoperitoneum, hemopericardium, severe gastrointestinal bleeding, hemorrhagic stroke, retroperitoneal hematoma; and minor hemorrhage complications included subcutaneous bleeding, epistaxis, microscopic hematuria, minor bleeding in stools, mild ocular bleeding, mild hemoptysis, gingival bleeding. To determine the validity of this checklist, the content validity method was used, and for this purpose the checklist was provided to 8 specialists (cardiologists, hematologists, and pharmacologists) and they were asked to express their views on the checklist items and, if there was a need to modify or edit, to comment. Finally, the CVR value was calculated, and was found to be 0.75 .

\section{Data collection}

The investigator responsible for the collection of data was unaware of the randomization and grouping process. At the beginning of the study and before any intervention, individuals' data were collected using a demographic and clinical information questionnaire. Following the intervention and after the patient was discharged from the hospital for 6 consecutive months, information about the results of the INR test and the incidence of bleeding events was recorded every month.

\section{Data analysis}

Data were analyzed using the independent $t$-test and $\chi^{2}$ test in SPSS16 software at a significance level of 0.05. 


\section{Results}

At the beginning of the study, 160 heart valve replacement patients were included in the study and were randomly divided into control $(n=80)$ and intervention $(n=80)$ groups. During the follow-up period, 5 patients died (intervention group, $n=2$; control group, $n=3$ ), 2 patients withdrew from the study process (intervention group, $n=1$; control group, $n=1$ ), and 4 patients was lost to follow-up (intervention group, $n=3$; control group, $n=1$ ). Finally, information and data of 149 participants (intervention group, $n=74$; control group, $n=75$ ) were analyzed.

\section{Participant demographic characteristics}

Table II shows the demographic characteristics of 149 participants by grouping and the two groups are compared. As shown in the table, the two groups in terms of age, height and weight, gender, marital status, occupation, education, and place of residence (city or village) were not significantly different and were homogeneous $(p>0.05)$.

\section{Participant clinical characteristics}

Table III shows the clinical characteristics of the participants and the two groups are compared. The mean BMI of the two control and intervention groups was $24.92 \pm 3.20$

Table II. Demographic characteristics of patients in both groups

\begin{tabular}{|c|c|c|c|}
\hline Variable & $\begin{array}{l}\text { Control } \\
(n=75)\end{array}$ & $\begin{array}{l}\text { Intervention } \\
\quad(n=74)\end{array}$ & $P$-value \\
\hline Age (mean \pm SD) & $55.57 \pm 12.37$ & $56.81 \pm 12.53$ & $0.545^{\star}$ \\
\hline Height (mean \pm SD) & $167.05 \pm 6.59$ & $166.16 \pm 7.03$ & $0.426^{*}$ \\
\hline Weight (mean \pm SD) & $69.57 \pm 9.80$ & $70.02 \pm 8.76$ & $0.766^{*}$ \\
\hline Gender n (\%): & & & $0.795^{\star *}$ \\
\hline Male & $42(56)$ & $43(58.1)$ & \\
\hline Female & $33(44)$ & $31(41.9)$ & \\
\hline Marital status $n(\%)$ : & & & $0.501^{* *}$ \\
\hline Single & $12(16)$ & $9(12.16)$ & \\
\hline Married & $63(84)$ & $65(87.84)$ & \\
\hline Employment $n(\%)$ : & & & $0.478^{\star *}$ \\
\hline Unemployed & $34(45.33)$ & $35(47.30)$ & \\
\hline Self-employed & $34(45.33)$ & $28(37.84)$ & \\
\hline Office worker & $7(9.34)$ & $11(14.86)$ & \\
\hline Education $n(\%)$ : & & & $0.194^{\star \star}$ \\
\hline Illiterate & $31(41.33)$ & $41(55.40)$ & \\
\hline Primary school & $22(29.33)$ & $16(21.62)$ & \\
\hline Diploma & $15(20)$ & $8(10.81)$ & \\
\hline Academic & $7(9.34)$ & $9(12.17)$ & \\
\hline Residence $n(\%)$ : & & & $0.06^{\star *}$ \\
\hline Rural & $29(38.67)$ & $40(52.5)$ & \\
\hline Urban & 46 (61.33) & $34(47.5)$ & \\
\hline
\end{tabular}

*Independent $t$-test, ${ }^{* *} \chi^{2}$ test. and $25.56 \pm 4.32$ respectively, which were not significantly different between the two groups ( $p=0.307$ ). $37.6 \%$ of participants reported high blood pressure, $13.4 \%$ diabetes, and $22.8 \%$ hyperlipidemia in their clinical history. In this regard, there was no significant difference between the two groups ( $p>0.05$ ). Among the participants, $24.8 \%$ reported a smoking habit and $10.7 \%$ reported a history of alcohol consumption, but the two groups did not differ significantly in this regard $(p>0.05)$. Fifty-five percent of participants had mitral valve replacement (MVR), $27.5 \%$ had aortic valve replacement (AVR), $2.7 \%$ had tricuspid valve replacement (TVR) and $14.8 \%$ had bivalve replacement (BVR), and participants in the two groups did not differ significantly in the position of the valve replaced ( $p=0.969$ ). Participants in the control and intervention groups were hospitalized for 8.62 \pm 2.48 and $9.02 \pm 2.39$ days, respectively $(p=0.318$ ) (Table III).

\section{Intergroup comparison of INR levels during 6 months after surgery}

Table IV compares the level of INR in the participants. As shown in the table, in the first, second, fourth, fifth, and

Table III. Demographic characteristics of patients in both groups

\begin{tabular}{|c|c|c|c|}
\hline Variable & $\begin{array}{l}\text { Control } \\
(n=80)\end{array}$ & $\begin{array}{l}\text { Intervention } \\
\quad(n=80)\end{array}$ & $P$-value \\
\hline $\mathrm{BMI}($ mean $\pm \mathrm{SD})$ & $24.92 \pm 3.20$ & $25.56 \pm 4.32$ & $0.307^{*}$ \\
\hline Hypertension $n$ (\%): & & & $0.281^{* *}$ \\
\hline Yes & $25(33.33)$ & 31 (41.89) & \\
\hline No & $50(66.67)$ & $43(58.11)$ & \\
\hline Diabetes $n(\%)$ : & & & $0.608^{* *}$ \\
\hline Yes & $9(11.84)$ & $11(14.86)$ & \\
\hline No & $66(88.16)$ & $63(85.13)$ & \\
\hline Dyslipidemia $n$ (\%): & & & $0.729^{* *}$ \\
\hline Yes & $18(24)$ & $16(21.62)$ & \\
\hline No & $57(76)$ & $58(78.38)$ & \\
\hline Smoking habit $n(\%)$ : & & & $0.538^{* *}$ \\
\hline Yes & $17(22.67)$ & $20(27.03)$ & \\
\hline No & $58(77.33)$ & $54(72.97)$ & \\
\hline Alcohol consumption $n$ (\%): & & & $0.277^{\star *}$ \\
\hline Yes & $6(8)$ & $10(13.51)$ & \\
\hline No & $69(92)$ & $64(86.49)$ & \\
\hline
\end{tabular}

\begin{tabular}{lccc} 
Valve position $n(\%):$ & & $0.969^{* *}$ \\
\cline { 1 - 3 } MVR & $40(53.33)$ & $42(56.75)$ & \\
\cline { 1 - 3 } AVR & $21(28)$ & $20(27.03)$ & \\
\cline { 1 - 3 } TVR & $2(2.67)$ & $2(2.70)$ & \\
\cline { 1 - 3 } BVR & $12(16)$ & $10(13.52)$ & \\
\cline { 1 - 3 } Hospital stay (mean \pm SD) & $8.62 \pm 2.48$ & $9.02 \pm 2.39$ & $0.318^{*}$
\end{tabular}

*Independent $t$-test, ${ }^{* *} \chi^{2}$ test; $\mathrm{BMI}$ - body mass index, MVR - mitral valve replacement, AVR - aortic valve replacement, TVR - tricuspid valve replacement, BVR - bivalve replacement. 
Self-care training and informational support of patients with a mechanical heart valve on the international normalized ratio and bleeding complications

Table IV. Intergroup comparison of INR levels during 6 months after surgery

\begin{tabular}{|c|c|c|c|c|}
\hline Parameter & $\begin{array}{l}\text { Range } \\
\text { of INR }\end{array}$ & $\begin{array}{l}\text { Control } \\
(n=75)\end{array}$ & $\begin{array}{l}\text { Intervention } \\
\quad(n=74)\end{array}$ & $P$-value \\
\hline \multirow{2}{*}{$\begin{array}{l}\text { First } \\
\text { follow-up }\end{array}$} & ITT n (\%) & $40(53.33)$ & $52(70.27)$ & \multirow[t]{2}{*}{$0.033^{*}$} \\
\hline & OTT $n(\%)$ & $35(46.7)$ & $22(29.73)$ & \\
\hline \multirow{2}{*}{$\begin{array}{l}\text { Second } \\
\text { follow-up }\end{array}$} & ITT $n$ (\%) & $43(57.33)$ & $54(72.97)$ & \multirow[t]{2}{*}{$0.045^{\star}$} \\
\hline & OTT $n(\%)$ & $32(42.67)$ & $20(27.03)$ & \\
\hline \multirow{2}{*}{$\begin{array}{l}\text { Third } \\
\text { follow-up }\end{array}$} & ITT $n(\%)$ & $42(56)$ & $52(70.27)$ & \multirow[t]{2}{*}{$0.071^{*}$} \\
\hline & OTT $n(\%)$ & $33(44)$ & $22(29.73)$ & \\
\hline \multirow{2}{*}{$\begin{array}{l}\text { Fourth } \\
\text { follow-up }\end{array}$} & ITT $n(\%)$ & $47(62.67)$ & 59 (79.73) & \multirow[t]{2}{*}{$0.022^{*}$} \\
\hline & OTT $n(\%)$ & $28(37.33)$ & $15(20.3)$ & \\
\hline \multirow{2}{*}{$\begin{array}{l}\text { Fifth } \\
\text { follow-up }\end{array}$} & ITT $n(\%)$ & $51(68)$ & $61(82.43)$ & \multirow[t]{2}{*}{$0.041^{*}$} \\
\hline & OTT $n$ (\%) & $24(32)$ & $13(17.57)$ & \\
\hline \multirow{2}{*}{$\begin{array}{l}\text { Sixth } \\
\text { follow-up }\end{array}$} & ITT $n(\%)$ & 49 (65.33) & 59 (79.73) & \multirow[t]{2}{*}{$0.049^{\star}$} \\
\hline & OTT $n(\%)$ & $26(34.67)$ & $15(20.27)$ & \\
\hline
\end{tabular}

${ }^{*} \chi^{2}$ test; ITT - in therapeutic target, OTT - out of therapeutic target.

sixth months, the frequency of INR levels in the therapeutic target range was significantly higher in patients in the intervention group than in the control group $(p<0.05)$. In the third month, although the frequency of INR levels in the therapeutic target range was higher in the intervention group, this difference was not significant $(p=0.071)$.

\section{Intergroup comparison of the prevalence of bleeding during 6 months after surgery}

Table $V$ compares the prevalence of minor and major bleeding in the two groups over a 6-month follow-up. As shown in the table, during the 6 months of follow-up, the frequency of both types of bleeding (minor and major) in the intervention group was lower than in the control group, but this difference was not statistically significant $(p>0.05)$.

\section{Discussion}

In this study during a 6-month follow-up program, to determine the effect of self-care training and informational support of heart valve replacement patients on INR and bleeding complications, the INR level data and bleeding complications of 149 participants in two groups, control and intervention, were compared. This is the first study of training on self-care and informational support for mechanical heart valve patients that has directly investigated the effects of this method of care on INR levels and the incidence of bleeding complications during a clinical trial. One of the strengths of this study is that at the beginning of the study to determine the topics of self-care education of patients in the target group, the training needs assessment was performed and finally a training package which was specific to patients with mechanical valve replacement was used. In this way, patients were introduced to care measures that had a positive effect on patients) recovery process.
Table V. Intergroup comparison of the prevalence of bleeding during 6 months after surgery

\begin{tabular}{lcccc} 
Variable & $\begin{array}{c}\text { Incidence } \\
\text { of bleeding }\end{array}$ & $\begin{array}{c}\text { Control } \\
(n=75)\end{array}$ & $\begin{array}{c}\text { Intervention } \\
(n=74)\end{array}$ & P-value \\
follow-up & MajH \% & $5.33 \%$ & $2.70 \%$ & $0.414^{*}$ \\
\cline { 2 - 5 } $\begin{array}{lcccc}\text { Second } \\
\text { follow-up }\end{array}$ & MinH \% & $13.33 \%$ & $8.10 \%$ & $0.303^{*}$ \\
\cline { 2 - 5 } & MinH \% & $4 \%$ & $1.35 \%$ & $0.317^{*}$ \\
\hline Third & $14.6 \%$ & $6.75 \%$ & $0.119^{*}$ \\
\hline follow-up & MajH \% & $2.66 \%$ & 2.70 & $0.989^{*}$ \\
\cline { 2 - 5 } $\begin{array}{lccc}\text { Fourth } \\
\text { follow-up }\end{array}$ & MajH \% & $13.33 \%$ & $6.75 \%$ & $0.182^{*}$ \\
\cline { 2 - 5 } & MinH \% & $4 \%$ & $1.35 \%$ & $0.317^{*}$ \\
\hline $\begin{array}{l}\text { Fifth } \\
\text { follow-up }\end{array}$ & MajH \% & $2.66 \%$ & $6.75 \%$ & $0.273^{*}$ \\
\cline { 2 - 5 } & MinH \% & $9.33 \%$ & $4.05 \%$ & $0.157^{*}$ \\
\hline $\begin{array}{l}\text { Sixth } \\
\text { follow-up }\end{array}$ & MajH \% & $2.66 \%$ & $1.35 \%$ & $0.568^{*}$ \\
\cline { 2 - 5 } & MinH \% & $8 \%$ & $4.05 \%$ & $0.312^{*}$ \\
\hline
\end{tabular}

${ }^{*} \chi^{2}$ test; MajH - major hemorrhage, MinH - minor hemorrhage.

The results of this study showed that patients will experience the effectiveness of self-care if they become familiar with the basic and scientific methods of self-care and follow-up in the form of a support program and receive the necessary information that is specific to each patient.

One of the benefits of self-care for heart valve replacement patients which can be deduced from the results of this study is that in the group that received self-care training and informational support interventions, the frequency of the therapeutic target range of INR was significantly higher than in the control group. This finding is consistent with the results of educational studies that have examined the effect of self-management education [21-23].

Another benefit of self-care that the results of this study show is the reduction in the incidence of bleeding complications. In this study, bleeding complications in the intervention group receiving self-care educational and supportive interventions were less frequent than in the control group, but this difference was not statistically significant. This finding contradicts the results of previous studies which have shown that a self-management training program can significantly reduce bleeding complications [24-26]. This discrepancy may be related to the difference in sample size of the present study with previous studies, because in the present study a smaller sample than the previous studies has been studied. Also, the results of this study are consistent with the results of previous studies showing that, in terms of clinical outcomes, such as the incidence of major complications and mortality by any cause, patients' self-management in a real-life setting seems to be a very good alternative in properly trained patients $[27,28]$. Complications of bleeding are less frequent in these patients [29]; therefore, to show a statistically significant difference between the two groups in terms of the prevalence of bleeding, it is necessary to perform interventions on 
a large group of participants. Accordingly, in the present study, despite the lower incidence of bleeding in the intervention group, due to the small sample size, a significant difference between the two groups in terms of bleeding was not found.

There are some limitations to our study. The first is the small sample size, because the bleeding variable is less prevalent in the study population and in order to determine the effect of interventions, it is necessary to take a large sample size. Another limitation of the present study is the short follow-up period (6 months); despite this limitation, it is not possible to evaluate the mid- and long-term results of the interventions. Accordingly, it is suggested that more extensive studies be conducted in this field with a larger sample size and longer follow-up time.

\section{Conclusions}

The results of this study showed that self-care training and informational support of heart valve replacement patients during the postoperative period have positive effects on the patients' clinical condition. Based on the results, patients who have received proper self-care training and receive informational support from medical staff during the postoperative period are more likely to experience the therapeutic target range of INR. It can also be concluded that proper self-care can reduce the incidence of bleeding complications in patients with a mechanical heart valve. Therefore proper self-care training can lead to improvement of the patient's condition and a safe anticoagulant regimen.

By integrating self-care education and informational support for heart valve replacement patients, the nursing system can institutionalize self-care in patients, which improves the patient's clinical condition. Appropriate educational and supportive interventions can increase the ability of patients to replace heart valves and reciprocally reduce postoperative complications. Also, if educational interventions are based on the educational needs of the target patients, they have a stronger effect.

\section{Acknowledgments}

This study has been adapted from an MSc thesis at Hamadan University of Medical Sciences.

The study was funded by Vice-chancellor for Research and Technology, Hamadan University of Medical Sciences (No. 9805223880).

\section{Disclosure}

The authors report no conflict of interest.

\section{References}

1. Tiede DJ, Nishimura RA, Gastineau DA, Mullany CJ, Orszulak TA, Schaff HV. Modern management of prosthetic valve anticoagulation. Paper presented at: Mayo Clinic Proceedings 1998.

2. Hirsh J, Dalen JE, Anderson DR, Poller L, Bussey H, Ansell J, Deykin D. Oral anticoagulants: mechanism of action, clinical effectiveness, and optimal therapeutic range. Chest 2001; 119 (1 Suppl): 8S-21S.
3. Ageno W, Gallus AS, Wittkowsky A, Crowther M, Hylek EM, Palareti G. Oral anticoagulant therapy: antithrombotic therapy and prevention of thrombosis: American College of Chest Physicians evidence-based clinical practice guidelines. Chest 2012; 141: e44S-88S.

4. Joint Task Force on the Management of Valvular Heart Disease of the European Society of Cardiology (ESC); European Association for Cardio-Thoracic Surgery (EACTS); Vahanian A, Alfieri O, Andreotti F, Antunes MJ, BarónEsquivias G, Baumgartner H, Borger MA, Carrel, TP, De Bonis M, Evangelista A, Falk V, lung B, Lancellotti P, Pierard L, Price S, Schäfers HJ, Schuler G, Stepinska J, Swedberg K, Takkenberg J, Von Oppell UO, Windecker S, Zamorano JL, Zembala M. Guidelines on the management of valvular heart disease (version 2012) The Joint Task Force on the Management of Valvular Heart Disease of the European Society of Cardiology (ESC) and the European Association for Cardio-Thoracic Surgery (EACTS). Eur Heart J 2012; 33: 2451-96.

5. Nishimura RA, Otto CM, Bonow RO, Carabello BA, Erwin 3rd JP, Fleisher LA, Jneid H, Mack MJ, McLeod CJ, O'Gara PT, Rigolin VH, Sundt 3rd TM, Thompson A. 2017 AHA/ACC focused update of the 2014 AHA/ACC guideline for the management of patients with valvular heart disease: a report of the American College of Cardiology/American Heart Association Task Force on Clinical Practice Guidelines. J Am Coll Cardiol 2017; 70: 252-89.

6. Pattacini C, Manotti C, Pini M, Quintavalla R, Dettori AG. A comparative study on the quality of oral anticoagulant therapy (warfarin versus acenocoumarol). Thrombosis Haemostasis 1994; 71: 188-91.

7. Bryk AH, Plens K, Undas A. Prediction of unstable anticoagulation with acenocoumarol versus warfarin in atrial fibrillation. Cardiol J 2017; 24: 477-83.

8. Aikins J, Koomson A, Ladele M, Al-Nusair L, Ahmed A, Ashry A, Harky A. Anticoagulation and antiplatelet therapy in patients with prosthetic heart valves. J Card Surg 2020; 35; 3521-9.

9. Kido K, Ball J. Optimal intensity of warfarin therapy in patients with mechanical aortic valves. J Pharm Practice 2019; 32: 93-8.

10. Eikelboom JW, Wallentin L, Connolly SJ, Ezekowitz M, Healey JS, Oldgren J, Yang S, Alings M, Kaatz S, Hohnloser SH, Diener HC, Franzosi MG, Huber K, Reilly P, Varrone J, Yusuf S. Risk of bleeding with 2 doses of dabigatran compared with warfarin in older and younger patients with atrial fibrillation: an analysis of the randomized evaluation of long-term anticoagulant therapy (RE-LY) trial. Circulation 2011; 123: 2363-72.

11. Zhang J, Tian L, Huang J, Huang S, Chai T, Shen J. Cytochrome P450 2 C9 gene polymorphism and warfarin maintenance dosage in pediatric patients: a systematic review and meta-analysis. Cardiovasc Therapeutics 2017; 35: 26-32.

12. Gibler WB, Racadio JM, Hirsch AL, Roat TW. Management of severe bleeding in patients treated with oral anticoagulants: proceedings monograph from the Emergency Medicine Cardiac Research and Education Group-International Multidisciplinary Severe Bleeding Consensus Panel October 20, 2018. Crit Pathways Cardiol 2019; 18: 143-66.

13. Pourafkari L, Baghbani-Oskouei A, Taban-Sadeghi M, Salamzadeh V, Ghaffari S, Savadi-Oskouei S, Nader ND. Factors influencing various aspects of patients' knowledge of oral anticoagulation. J Cardiovasc Pharmacol 2018; 71: 174-9.

14. Talboom-Kamp EP, Verdijk NA, Kasteleyn MJ, Harmans LM, Talboom IJSH, Numans ME, Chavannes NH. Effect of a combined education and eHealth programme on the control of oral anticoagulation patients (PORTALS study): a parallel cohort design in Dutch primary care. BMJ Open 2017; 7: e017909.

15. Di Minno A, Frigerio B, Spadarella G, Ravani A, Sansaro D, Amato M, Kitzmiller JP, Pepi M, Tremoli E, Baldassarre D. Old and new oral anticoagulants: food, herbal medicines and drug interactions. Blood Rev 2017; 31: 193-203.

16. Boyde M, Peters R, New N, Hwang R, Ha T, Korczyk D. Self-care educational intervention to reduce hospitalisations in heart failure: a randomised controlled trial. Eur J Cardiovasc Nurs 2018; 17: 178-85.

17. Boyde M, Peters R, Hwang R, Korczyk D, Ha T, New N. The self-care educational intervention for patients with heart failure: a study protocol. J Cardiovasc Nurs 2017; 32: 165-70.

18. Bartos S. Self-Care Behaviors of Women Living with Heart Failure: A Mixed Methods Study. Doctoral Dissertations 2016.

19. Whitlock RP, Sun JC, Fremes SE, Rubens FD, Teoh KH. Antithrombotic and thrombolytic therapy for valvular disease: antithrombotic therapy and prevention of thrombosis: American College of Chest Physicians Evidence-Based Clinical Practice Guidelines. Chest 2012; 141: e576S-600S.

20. de Campos NLKL. Comparison of the occurrence of thromboembolic and bleeding complications in patients with mechanical heart valve prosthesis with one and two leaflets in the mitral position. Rev Brasil Cir Cardiovasc 2014; 29: 59. 
Self-care training and informational support of patients with a mechanical heart valve on the international normalized ratio and bleeding complications

21. Zandi S, Imani B, Safarpor G, Khazaei S. Self-management of patients with heart valve replacement and its clinical outcomes: a systematic review. Kardiochir Torakochir Pol 2021; 18: 40-49.

22. Eitz T, Schenk S, Fritzsche D, Bairaktaris A, Wagner O, Koertke H, Koerfer R. International normalized ratio self-management lowers the risk of thromboembolic events after prosthetic heart valve replacement. Ann Thoracic Surg 2008; 85: 949-55.

23. Thompson JL, Burkhart HM, Daly RC, Dearani JA, Joyce LD, Suri RM, Schaff HV. Anticoagulation early after mechanical valve replacement: improved management with patient self-testing. J Thorac Cardiovasc Surg 2013; 146: 599-604.

24. Christensen TD, Skjøth F, Nielsen PB, Maegaard M, Grove EL, Larsen TB. Selfmanagement of anticoagulant therapy in mechanical heart valve patients: a matched cohort study. Ann Thorac Surg 2016; 101: 1494-9.

25. Christensen TD, Andersen NT, Attermann J, Hjortdal VE, Maegaard M, Hasenkam JM. Mechanical heart valve patients can manage oral anticoagulant therapy themselves. Eur J Cardiothorac Surg 2003; 23: 292-8.
26. Mair H, Sachweh J, Sodian R, Brenner P, Schmoeckel M, Schmitz C, Reichart B, Daebritz S. Long-term self-management of anticoagulation therapy after mechanical heart valve replacement in outside trial conditions. Interact Cardiovasc Thorac Surg 2012; 14: 253-7.

27. Corrochano M, Jiménez B, Millón J, Gich I, Rambla M, Gil E, Caparros P, Macho R, Souto JC. Patient self-management of oral anticoagulation with vitamin $\mathrm{K}$ antagonists in everyday practice: clinical outcomes in a single centre cohort after long-term follow-up. BMC Cardiovasc Disord 2020; 20: 1-13.

28. Grove EL, Skjøth F, Nielsen PB, Christensen TD, Larsen TB. Effectiveness and safety of self-managed oral anticoagulant therapy compared with direct oral anticoagulants in patients with atrial fibrillation. Sci Reports 2018; 8: 15805.

29. Rubboli A, Becattini C, Verheugt FW. Incidence, clinical impact and risk of bleeding during oral anticoagulation therapy. World J Cardiol 2011; 3: 351. 